\title{
PENERAPAN NONPREEMPTIVE GOAL PROGRAMMING PADA PENJADWALAN SATUAN PENGAMANAN
}

\author{
DANDI MANOY $^{1 *}$, ViCtOR R. SUlANGI ${ }^{2}$, JAMES U. L. MANGOBI ${ }^{3}$ \\ 1,2,3 Jurusan Matematika, FMIPA, Universitas Negeri Manado \\ *dandymanoy2712@gmail.com
}

\begin{abstract}
ABSTRAK
Penjadwalan satuan pengamanan secara konvensional (bersifat manual) merupakan masalah pada sistem manajemen lembaga tersebut. Sehingga, melanggar ataupun tidak memenuhi ketentuan-ketentuan yang ditetapkan dalam pembuatan jadwal. Pada makalah ini Kendala-kendala penjadwalan satuan pengamanan dibagi menjadi, yaitu kendala utama dan kendala tambahan yang akan dimodelkan dalam bentuk Linear Programming, kemudian diselesaiakan dengan Nonpreemptive Goal Programming. Data yang didapatkan antara lain jumlah regu, banyaknya wilayah, dan pembagian shift kerja. Terdapat 3 variasi penjadwalan yang dibentuk dimana ketiga variasi tersebut memiliki perbedaan pada jumlah regu ataupun jumlah shift kerja. Penjadwalan yang dihasilkan menunjukan pemerataan dalam jam kerja dan maksimal hari kerja secara berturut-turut $\leq 5$ setiap regu. Jadwal yang dihasilkan optimal berdasarkan jumlah regu, banyaknya wilyah penjagaan dan shift kerja yang diterapkan.
\end{abstract}

Kata Kunci: Penjadwalan, Nonpreemptive Goal Programming

\begin{abstract}
Conventional (manual) scheduling of security forces is a problem with the institution's management system. Thus, violating or not fulfilling the provisions set out in scheduling. In this paper, security unit scheduling constraints are divided into, namely the main constraints and additional constraints which will be modeled in the form of Linear Programming, then resolved with Nonpreemptive Goal Programming. The data obtained include the number of teams, the number of regions, and the distribution of work shifts. There are 3 variations of the schedule formed where the three variations have differences in the number of teams or the number of work shifts. The resulting scheduling shows evenness in working hours and maximum working days in a row $\leq 5$ for each team. The resulting schedule is optimal based on the number of teams, the number of guarding areas and work shifts applied.
\end{abstract}

Keywords: Scheduling; Nonpreemptive Goal Programming 


\section{Pendahuluan}

Penjadwalan satuan pengamanan secara konvensional yaitu dengan menebak-nebak kemungkinan yang ada merupakan masalah pada sistem manajemen lembaga tersebut. Sehingga, melanggar ataupun tidak memenuhi ketentuan-ketentuan yang ditetapkan dalam pembuatan jadwal. Hal ini akan berdampak pada jam dan shift kerja pada masing-masing petugas tidak merata. Penjadwalan yang dilakukan secara manual akan dirasa kurang efektif apabila terbentur dengan input data yang banyak dan parameter yang kompleks. Selain, membutuhkan ketelitian yang sangat tinggi serta estimasi waktu yang relatif tidak sedikit, metode ini juga memungkinkan terjadinya kesalahan. Proses manual dapat menimbulkan masalah seperti ketidakadilan bagi petugas dan akan berdampak pada kecemburuan antar petugas [1].

Dalam hal ini penting untuk melakukan perencanaan yang cukup matang serta diperlukan metode penyelesaian yang bisa merangkum ketentuan-ketentuan tersebut sehingga diperoleh penjadwalan yang optimal berdasarkan faktor-faktor di lapangan [2]. Penjadwalan yang kurang optimal dapat menyebabkan jam kerja yang meningkat, menyebabkan kesehatan yang terganggu dan juga berdampak pada kinerja dari petugas. Faatih [3] membuat model penjadwalan satuan pengamanan kebentuk Integer Linear Programming. Mardiah [4] menghasilkan jadwal yang optimal dengan menggunakan Nonpreemptive Goal Programming.

Berdasarkan observasi yang dilakukan di Universitas Negeri Manado, penentuan jadwal satuan pengamanan dilakukan secara manual dan untuk penjagaan hanya pada wilayah-wilayah tertentu tidak secara menyeluruh. Ketentuan-ketentuan yang didapatkan saat wawancara yaitu, petugas shift malam tidak mendapatkan shift pagi diberikutnya. Berdasarkan kendala tersebut, jadwal satuan pengamanan harus mengoptimalkan berbagai kendala-kendala. Tetapi, masalah penjadwalan yang memperhatikan shift kerja dan jumlah penjagaan wilayah sulit untuk diselesaikan secara manual. Oleh karena itu, pada penelitian ini kendala-kendala dalam penjadwalan dimodelkan dalam bentuk goal programming dan diselesaian dengan nonpreemptive goal programming. Proses komputasi menggunakan software LINGO 11.0.

\section{Tinjauan Pustaka}

\subsection{Linear Programming}

Menurut [5], Linear programming merupakan masalah optimasi dimana fungsi tujuan belum diketahui dan kendala-kendalanya terdiri dari persamaan dan pertidaksamaan linear. Bentuk dari batasan dari setiap masalah mungkin berbeda, tetapi linear programming dapat ditransformasikan kedalam bentuk standar dibawah ini:

Fungsi tujuan:

$$
\text { minimize } c_{1} x_{1}+c_{2} x_{2}+\cdots+c_{n} x_{n}
$$

Batasan

$$
\begin{gathered}
a_{11} x_{1}+a_{12} x_{2}+\cdots+a_{1 n} x_{n}=b_{1} \\
a_{21} x_{1}+a_{22} x_{2}+\cdots+a_{2 n} x_{n}=b_{2} \\
\cdot \\
\cdot \\
a_{m 1} x_{1}+a_{m 2} x_{2}+\cdots+a_{m n} x_{n}=b_{m}
\end{gathered}
$$


di mana $\quad x_{1} \geq 0, x_{2} \geq 0, \ldots, x_{n} \geq 0$

Linear programming dapat dipelajari secara aljabar maupun geometris. Kedua pendekatan itu ekivalen, tetapi dalam menentukan solusi masalah tertentu dapat dipilih pendekatan yang sesuai [6]. Solusi yang didapatkan mungkin memenuhi semua kendala (feasible solution) atau setidaknya melanggar satu kendala (infeasible solution) [7].

\subsection{Goal Programming}

Prinsip dasar goal programming ialah mengubah model linear yang memiliki fungsi objektif lebih dari satu, kedalam bentuk fungsi objektif tunggal dan memastikan solusi yang terdekat dengan tujuan yang akan dicapai [8]. Secara umum terdapat dua teknik untuk menyelesaikan permasalahan goal programming yaitu, preemptive goal programming dan nonpreemptive goal programming (weights method). Kedua metode tersebut didasarkan pada respresentasi berbagai tujuan dengan fungsi tujuan tunggal.

Dalam weights method fungsi tujuan merupakan jumlah bobot fungsi yang mewakili tujuan masalah. Metode preemptive dimulai dengan memprioritaskan tujuan dalam urutan kepentingannya, kemudian mengoptimalkan tujuan satu per satu dalam urutan prioritas dengan cara tidak menurunkan solusi dengan prioritas yang lebih tinggi. Tidak ada metode lebih unggul dari pada yang lain, karena kedua teknik tersebut memerlukan preferensi pengambilan keputusan yang berbeda [9].

Fungsi objektif goal programing dengan metode nonpreemptive adalah meminimumkan nilai dari variabel-variabel deviasi.

$$
\min z=\sum_{t} w_{t} d_{t}^{+}+\sum_{t} w_{t} d_{t}^{-}
$$

Kendala utama:

$$
f_{j}\left(x_{i}\right) \leq=\geq F_{j}, \quad \forall i, j F_{j}
$$

Kendala tambahan:

Dengan :

$$
g_{j}\left(x_{i}\right)+d_{t}^{-}-d_{t}^{+}=G_{j}, \quad \forall i, j
$$

$\boldsymbol{d}_{t}^{+} \quad=$ Variabel yang menyatakan kelebihan dari nilai tujuan ke-t.

$\boldsymbol{d}_{t}^{-} \quad=$ Variabel yang menyatakan kekurangan dari nilai tujuan ke-t.

$\boldsymbol{w}_{t} \quad=$ Bobot variabel deviasi.

$\boldsymbol{g}_{j}, \boldsymbol{f}_{j}=$ Persamaan kendala.

$\boldsymbol{x}_{i} \quad=$ Variabel keputusan.

\section{Prosedur Penelitian}

Penelitian ini merupakan penelitian operasional eksperimental, yaitu terdapat intervensi terhadap input dan proses data penelitian. Tahapan yang dilakukan adalah sebagai berikut:

1. Pengumpulan data berupa; Wilayah penempatan, banyaknya regu, shift, dan ketentuan dalam pembuatan jadwal.

2. Data disimplifikasi kebentuk Linear Programming ataupun Goal Programming.

3. Proses komputasi dengan software LINGO 11.0 untuk mendapatkan nilai-nilai variabel keputusan.

4. Interpretasi dan kesimpulan 


\section{Hasil}

\subsection{Deskripsi Masalah}

Dalam penjadwalan satuan pengamanan di Universitas Negeri Manado menggunakan sistem shift. Pihak kampus membagi jam kerja satuan pengamanan menjadi 2 shift, yaitu pagi dan malam. Shift pagi mulai pukul 07.00 - 19.00, sedangkan shift malam pukul $19.00-07.00$. Tetapi pada penelitian ini, akan ditinjau juga penjadwalan satuan pengamanan yang sesuai dengan peraturan perundang-undangan ketenagakerjaan Pasal 77 ayat 1 UU No. 13/2003 tentang ketenagakerjaan yaitu 3 shift. Shift pagi, siang dan malam. Untuk shift pagi mulai pukul 07.00-15.00, shift sore mulai pukul 15.00-23.00, dan shift malam mulai pukul 23.00-07.00.

Peneliti membagi 7 wilayah penjagaan secara menyeluruh di Univeritas Negeri Manado. Wilayah 1: Kantor pusat Universitas Negeri Manado, Gedung Kuliah Bersama, Perpustakaan, Auditorium, dan UPT-Kearsipan. Wilayah 2: Fakultas Teknik, Pendidikan Profesi Guru. Wilayah 3: Fakultas Ilmu Sosial, Fakultas Ekonomi, Pusat Komputer, Lembaga Penelitian dan Pengabdian Masyarakat. Wilayah 4: Fakultas Bahasa dan Seni, Asrama Bidik Misi, Jurusan Hukum. Wilayah 5: Fakultas Matematika dan Ilmu Pengetahuan Alam, Jurusan Kepelatihan. Wilayah 6: Fakultas Ilmu Keolahragaan, GOR UNIMA. Wilayah 7: Fakultas Ilmu Pendidikan, Program Pasca Sarjana. Asusmi dalam penempatan satuan pengamanan pada wilayah yaitu, tiap wilayah memiliki beban kerja yang sama, kecuali pada wilayah 1 . Penjadwalan pada penelitian menggunakan 30 hari kerja per bulan.

\subsection{Model}

\section{Indeks}

$i \quad=$ menyatakan wilayah $(i=1,2, \ldots, l)$

$x \quad=$ menyatakan hari $(x=1,2, \ldots, m)$

$y \quad=$ menyatakan regu $(y=1,2, \ldots, n)$

\section{Parameter}

$l \quad=$ banyaknya wilayah untuk penjagaan

$m$ = banyaknya hari yang digunakan dalam satu periode penjadwalan

$n \quad=$ banyaknya regu satuan pengamanan di kampus

$F_{x} \quad=$ banyaknya regu satuan pengamanan yang dibutuhkan pada shift pagi

$S_{x} \quad=$ banyaknya regu satuan pengamanan yang dibutuhkan pada shift sore

$T_{x} \quad=$ banyaknya regu satuan pengamanan yang dibutuhkan pada shift malam

$S \quad=$ jumlah shift dalam penjadwalan

$A \quad=$ jumlah hari kerja setiap regu pada wilayah tertentu

$L \quad=$ jumlah hari libur regu satuan pengamanan dalam penjadwalan

$M \quad=$ jumlah maksimal hari kerja regu satuan pengamanan berturut-turut dalam penjadwalan

$Z \quad=$ jumlah hari kerja setiap regu pada shift malam

$d_{t y}^{+} \quad=$ nilai yang menampung deviasi yang berada di atas tujuan ke- $t$ regu ke $y$

$d_{t y}^{-} \quad=$ nilai yang menampung deviasi yang berada di bawah tujuan ke- $t$ regu ke $y$

$d_{t x y}^{+} \quad=$ nilai yang menampung deviasi yang berada di atas tujuan ke- $t$ regu ke $y$ hari $x$

$d_{t x y}^{-} \quad=$ nilai yang menampung deviasi yang berada di bawah tujuan ke- $t$ regu ke $y$ hari $x$

Dengan $t=$ indeks tujuan $(t=1,2, \ldots, k)$ 


\section{Variabel Keputusan}

$N F_{x, y}=1$, jika regu $y$ bekerja pada shift pagi hari $x$

$N S_{x, y}=1$, jika regu $y$ bekerja pada shift sore hari $x$

$N T_{x, y}=1$, jika regu $y$ bekerja pada shift malam hari $x$

$N L_{x, y}=1$, jika regu $y$ libur

$W_{x, y}^{i}=1$, jika regu y bertugas pada wilayah $i$, hari $\mathrm{x}$

$N F_{x, y}=N S_{x, y}=N T_{x, y}=N L_{x, y}=W_{x, y}^{i}=0$, lainnya

\section{Kendala Utama}

1. Jumlah regu satuan pengamanan untuk setiap shift terpenuhi setiap harinya.

$$
\begin{aligned}
& \sum_{y=1}^{n} N F_{x, y}=F_{x}, \text { untuk shift } \text { pagi. } \\
& \sum_{y=1}^{n} N S_{x, y}=S_{x}, \text { untuk shift siang } \\
& \sum_{y=1}^{n} N T_{x, y}=T_{x}, \text { untuk shift malam }
\end{aligned}
$$

2. Setiap regu hanya mendapatkan satu shift kerja atau libur dalam satu hari.

$$
N F_{x, y}+N S_{x, y}+N T_{x, y}+N L_{x, y}=1
$$

3. Bertugas shift malam di suatu hari, tidak bisa mendapat shift pagi di berikutnya.

$$
N T_{x, y}+N F_{x+1, y} \leq 1
$$

4. Setiap regu mendapatkan jumlah libur sebanyak L.

$$
\sum_{x=1}^{m} N L_{x, y}=L
$$

5. Penempatan regu pada setiap wilayah terpenuhi setiap harinya.

$$
\sum_{y=1}^{n} W_{x, y}^{i}=S
$$

6. Setiap regu hanya mendapatkan satu wilayah penjagaan atau libur dalam satu hari.

$$
\sum_{i=1}^{l} W_{x, y}^{i}+N L_{x, y}=1
$$

7. Setiap regu mendapatkan penjagaan pada wilayah 1 sebanyak A.

$$
\sum_{x=1}^{m} W_{x, y}^{1}=A
$$




\section{Kendala Tambahan}

1. Setiap regu mendapatkan shift malam sebanyak Z.

$$
\left(\sum_{x=1}^{m} N T_{x, y}\right)+d_{1, x, y}^{-}-d_{1, x, y}^{+}=Z
$$

2. Regu tidak ditugaskan lebih dari 5 hari, secara berturut-turut.

$$
N L_{x, y}+N L_{x+1, y}+\cdots+N L_{x+5, y}+d_{2, x, y}^{-}-d_{2, x, y}^{+}=1
$$

Fungsi Objektif Secara umum fungsi objektif pada masalah penjadwalan satuan pengamanan ialah meminimumkan total kekurangan dan/atau kelebihan (deviasi) terhadap sasaran yang ingin dicapai. Penentuan prioritas suatu kendala berdasarkan bobot dari nilai variabel deviasi. Kendala tambahan 1 lebih di prioritaskan, sehingga bobot variabel 1 lebih tinggi dari yang lainnya, yaitu 4 dan 3 untuk lainnya. Sehingga, fungsi objektif pada masalah ini adalah:

$$
\operatorname{Min} z=4\left(\sum_{x=1}^{m} d_{1, x, y}^{+}+\sum_{x=1}^{m} d_{1, x, y}^{-}\right)+3 \sum_{x=1}^{m-5} \sum_{y=1}^{n} d_{2, x, y}^{-}
$$

\subsection{Penerapan Model}

Eksperimen 1 Pada tahap ini akan diteliti penjadwalan satuan pengamanan di Universitas Negeri Manado dengan 3 shift kerja per harinya, yaitu shift pagi, sore, dan malam. Perincian indeks dan parameter eksperimen 1 terdapat pada tabel 1.

Tabel 1 (Indeks dan Parameter eksperimen 1)

\begin{tabular}{|c|l|c|}
\hline $\begin{array}{c}\text { Indeks } \\
\text { atau } \\
\text { Parameter }\end{array}$ & \multicolumn{1}{|c|}{ Keterangan } & Nilai \\
\hline$i$ & Wilayah & \\
\hline$x$ & Hari & \\
\hline$y$ & Regu satuan pengamanan & 7 \\
\hline$L$ & Banyaknya wilayah untuk penjagaan & 21 \\
\hline$m$ & Banyaknya hari dalam penjadwalan & 7 \\
\hline$n$ & Banyaknya regu satuan pengamanan yang tersedia & 7 \\
\hline$F_{x}$ & $\begin{array}{l}\text { Banyaknya regu satuan pengamanan yang dibutuhkan pada shift pagi } \\
\text { di hari } x\end{array}$ & 7 \\
\hline$S_{x}$ & $\begin{array}{l}\text { Banyaknya regu satuan pengamanan yang dibutuhkan pada shift sore } \\
\text { di hari } x\end{array}$ & $\begin{array}{l}\text { Banyaknya regu satuan pengamanan yang dibutuhkan pada shift } \\
\text { malam di hari } x\end{array}$ \\
\hline$T_{x}$ & & \\
\hline
\end{tabular}




\begin{tabular}{|c|l|c|}
\hline$S$ & Jumlah Shift dalam penjadwalan & 3 \\
\hline$A$ & Jumlah hari kerja setiap regu pada wilayah 1 & 4,5 \\
\hline$L$ & $\begin{array}{l}\text { Jumlah hari libur regu satuan pengamanan dalam satu periode } \\
\text { penjadwalan }\end{array}$ & 0 \\
\hline$M$ & $\begin{array}{l}\text { Jumlah hari maksimal regu satuan pengamanan bekerja secara } \\
\text { berturut-turut }\end{array}$ & 5 \\
\hline$Z$ & Jumlah hari kerja setiap regu pada shift malam & 10 \\
\hline
\end{tabular}

Eksperimen 2 Tahap ini merupakan modifikasi eksperimen 1, yang perbedaannya ialah regu yang pada eksperimen 2 ini menjadi 28 regu. Untuk indeks, parameter, variabel keputusan, dan fungsi objektif pada eksperimen 2 sama dengan eksperimen 1, kecuali pada tabel 2:

Table 2 (Indeks dan Parameter eksperimen 2)

\begin{tabular}{|c|l|c|}
\hline $\begin{array}{c}\text { Indeks } \\
\text { atau } \\
\text { Parameter }\end{array}$ & \multicolumn{1}{|c|}{ Keterangan } & Nilai \\
\hline$n$ & Banyaknya regu satuan pengamanan yang tersedia & 28 \\
\hline$A$ & Jumlah hari kerja setiap regu pada wilayah 1 & 4,5 \\
\hline$L$ & $\begin{array}{l}\text { Jumlah hari libur regu satuan pengamanan dalam satu periode } \\
\text { penjadwalan }\end{array}$ & 7,8 \\
\hline$Z$ & Jumlah maksimal hari kerja setiap regu pada shift malam & 8 \\
\hline
\end{tabular}

Eksperimen 3 Pada tahap ini, yang dimodifikasi adalah shift kerjannya yaitu, hanya 2 shift pagi dan malam. Seperti yang diterapkan oleh pihak kampus. Untuk rincian waktu dapat dilihat ditabel dibawah ini:

Table 3 (Indeks dan Parameter eksperimen 3)

\begin{tabular}{|c|l|c|}
\hline $\begin{array}{c}\text { Indeks } \\
\text { atau } \\
\text { Parameter }\end{array}$ & \multicolumn{1}{|c|}{ Keterangan } & Nilai \\
\hline$i$ & Wilayah & \\
\hline$x$ & Hari & \\
\hline$y$ & Regu satuan pengamanan & 30 \\
\hline$m$ & Banyaknya hari dalam penjadwalan & 21 \\
\hline$n$ & Banyaknya regu satuan pengamanan yang tersedia & \\
\hline
\end{tabular}




\begin{tabular}{|c|l|c|}
\hline$F_{x}$ & $\begin{array}{l}\text { Banyaknya regu satuan pengamanan yang dibutuhkan pada shift pagi } \\
\text { di hari } x\end{array}$ & 7 \\
\hline$S_{x}$ & $\begin{array}{l}\text { Banyaknya regu satuan pengamanan yang dibutuhkan pada shift malam } \\
\text { di hari } x\end{array}$ & 7 \\
\hline$S$ & Jumlah Shift dalam penjadwalan & 2 \\
\hline$A$ & Jumlah hari kerja setiap regu pada wilayah 1 \\
\hline$L$ & $\begin{array}{l}\text { Jumlah hari libur regu satuan pengamanan dalam satu periode } \\
\text { penjadwalan }\end{array}$ & 10 \\
\hline$M$ & $\begin{array}{l}\text { Jumlah hari maksimal regu satuan pengamanan bekerja secara berturut- } \\
\text { turut }\end{array}$ & 5 \\
\hline$Z$ & Jumlah hari kerja setiap regu pada shift malam & 10 \\
\hline
\end{tabular}

\section{Pembahasan}

Kendala utama terpenuhi pada setiap Eksperimen, kecuali kendala tambahan. Eksperimen 1 menunjukan shift pagi maupun shift sore tidak sama pada regu tertentu, tetapi untuk jumlah shift pagi dan shift sore pada setiap regu adalah sama, yaitu 20. Sehingga, beban kerja dan durasi dalam penjagaan sama. Kendala tambahan ada yang tidak terpenuhi, yaitu maksimal hari kerja berturut-turut pada setiap regu $>5$ hari. Hal ini disebabkan karena jumlah regu sedikit untuk 3 shift penjagaan. Beban kerja setiap regu pada Eksperimen 1240 jam dalam 1 bulan.

Berbeda dengan Eksperimen 1, pada Eksperimen 2 terdapat kendala tambahan jumlah hari bekerja secara berturut-turut $\leq 5$ hari terpenuhi. Kemudian, shift libur ada tetapi belum merata. Sehingga, beban kerja dan durasi dalam penjagaan tidak sama. Beban kerja Eksperimen 2 yaitu 176 atau 184 jam dalam 1 bulan. Hasil Eksperimen 3 dengan shift berdasarakan pihak kampus memenuhi kendala utama dan tambahan. Jelas penjadwalan dengan 2 shift melanggar aturan kerja 8 jam dalam sehari dengan 240 jam kerja pada setiap regu. Tetapi karena keterbatasan jumlah regu sehingga aturan penjadwalan dengan 2 shift dapat dipergunakan berdasarkan kondisi dan pertimbangan tertentu.

\section{Kesimpulan}

Penjadwalan petugas satuan pengamann di Universitas Negeri Manado dapat dimodelakan dalam bentuk Linear Programming, kemudian diselesaikan dengan nonpreemptive goal programming. Hasil penjadwalan yang didapatkan optimum karena jumlah nilai $Z$ pada fungsi objektif minimal, berdasarkan shift maupun jumlah pada setiap eksperimen. Sehingga dapat digunakan berdasarkan kondisi dan pertimbangan tertentu untuk diimplementasikan dalam penjadwalan satuan pengamanan. 


\section{Daftar Pustaka}

[1] I. Irsyad, M. R. Katili, and N. Achmad, "Penerapan Metode Integer Linear Programming Pada Penjadwalan Karyawan,” J. Ris. dan Apl. Mat., vol. 4, no. 1, pp. 63-73, 2020.

[2] E. Damanik and P. Gultom, "Penerapan Metode Goal Programming Untuk Mengoptimalkan ProduksI," Saintia Mat., vol. 1, no. 2, pp. 117-128, 2013.

[3] Ii. A. Faatih, Penjadwalan pegawai menggunakan integer linear programming : studi kasus pada pegawai non operasional stasiun depok izzar arrisyad faatih. Bogor: Institut Pertanian Bogor, 2018.

[4] F. R. Mardiah, Penjadwalan Petugas Satuan Pengamanan Menggunakan Nonpreemptive Goal Programming dan Implementasinya di Intitut Pertanian Bogor. Bogor: Institut Pertanian Bogor, 2017.

[5] D. G. Luenberger and Y. Yinyu, Linear and Noninear Programming, Third. New York: Springer, 2008.

[6] G. Igor, S. G. Nash, and A. Sofer, Linear and Nonlinear Optimization, Second. Philadelphia: siam, 2009.

[7] F. S. Hillier and G. J. Lieberman, Introduction to Operations Research, Ninth. New York: McGraw-Hill, 2010.

[8] D. Jones and M. Tamiz, International Series in Operations Research \& Management Science Introduction. New York: Springer, 2010.

[9] H. A. Taha, Operation Reseach an Introduction, Tenth. London: Pearson, 2017. 